\title{
Restriction of dietary protein does not promote hepatic lipogenesis in lean or fatty pigs
}

\author{
Marta S. Madeira ${ }^{1} \dagger$, Virgínia M. R. Pires ${ }^{1} \dagger$, Cristina M. Alfaia ${ }^{1}$, Paula A. Lopes ${ }^{1}$, Susana V. Martins ${ }^{1}$, \\ Rui M. A. Pinto ${ }^{2}$ and José A. M. Prates ${ }^{1 *}$ \\ ${ }^{1}$ CIISA, Faculdade de Medicina Veterinária, Universidade de Lisboa, Avenida da Universidade Técnica, Alto da Ajuda, \\ 1300-477 Lisboa, Portugal \\ ${ }^{2}$ iMed.UL, Faculdade de Farmácia, Universidade de Lisboa, Alto da Ajuda, 1300-477 Lisboa, Portugal
}

(Submitted 21 September 2015 - Final revision received 17 December 2015 - Accepted 21 January 2016 - First published online 1 March 2016)

\section{Abstract}

The influence of genotype (lean $v$. fatty) and dietary protein level (normal $v$. reduced) on plasma metabolites, hepatic fatty acid composition and mRNA levels of lipid-sensitive factors is reported for the first time, using the pig as an experimental model. The experiment was conducted on forty entire male pigs (twenty lean pigs of Large White $\times$ Landrace $\times$ Pietrain cross-breed and twenty fatty pigs of Alentejana purebreed) from 60 to $93 \mathrm{~kg}$ of live weight. Each pig genotype was divided into two subgroups, which were fed the following diets: a normal protein diet (NPD) equilibrated for lysine ( $17.5 \%$ crude protein and $0.7 \%$ lysine) and a reduced protein diet (RPD) not equilibrated for lysine (13.1\% crude protein and $0.4 \%$ lysine). The majority of plasma metabolites were affected by genotype, with lean pigs having higher contents of lipids, whereas fatty pigs presented higher insulin, leptin and urea levels. RPD increased plasma TAG, free fatty acids and VLDL-cholesterol compared with NPD. Hepatic total lipids were higher in fatty pigs than in the lean genotype. RPD affected hepatic fatty acid composition but had a slight influence on gene expression levels in the liver. Sterol regulatory element-binding factor 1 was down-regulated by RPD, and fatty acid desaturase 1 (FADS1) and fatty acid binding protein 4 (FABP4) were affected by the interaction between genotype and diet. In pigs fed RPD, FADS1 was up-regulated in the lean genotype, whereas FABP4 increased in the fatty genotype. Although there is a genotype-specific effect of dietary protein restriction on hepatic lipid metabolism, lipogenesis is not promoted in the liver of lean or fatty pigs.

\section{Key words: Hepatic lipid metabolism: Fatty acid composition: Gene expression: Reduced protein diets: Pig genotype}

One of the most important livestock animals in the food industry is the $\mathrm{pig}^{(1)}$. To reduce carcass fatness and improve feed efficiency, pigs reared in intensive systems have become leaner exhibiting fast growth. Leaner pigs display low intramuscular fat (IMF) content, a key meat quality trait, and sensory properties of pork are negatively affected when IMF is reduced below $2-2.5 \%{ }^{(2)}$.

Recent studies have used reduced protein diets (RPD) or low lysine levels as the most successful nutritional strategies to enhance fat accumulation in skeletal muscle without increasing subcutaneous adipose tissue in pigs ${ }^{(3-5)}$. This finding relies on tissue-specific stimulation of lipogenic enzyme expressions under RPD, which in turn can lead to the increase of de novo fatty acid synthesis ${ }^{(3)}$. In addition, it is well known that dietary lysine deficiency reduces protein synthesis and increases the energy available for fat deposition ${ }^{(6)}$. This mechanism can be related to higher transcription levels of $P P A R \gamma$ and sterol regulatory element-binding factor 1 (SREBF1) found in the muscle of growing pigs fed low dietary lysine, thus promoting lipogenesis ${ }^{(7,8)}$. However, the effect of RPD and low lysine levels on hepatic fatty acid metabolism remains to be elucidated.

Liver, together with skeletal muscle and adipose tissue, plays a key role in the regulation of lipid metabolism in pigs ${ }^{(9)}$. It is the principal site of cholesterol synthesis and fatty acid oxidation, whereas de novo lipogenesis occurs essentially in both liver and adipose tissue ${ }^{(10)}$. Furthermore, the uptake of plasma NEFA released by adipose tissue is the predominant route by which fatty acids are supplied to the liver. Thus, plasma fatty acids should influence hepatic fatty acid composition and the expression of several proteins responsible for lipid metabolism ${ }^{(11)}$.

\footnotetext{
Abbreviations: ACACA, acetyl-CoA carboxylase $\alpha$; FABP4, fatty acid binding protein 4; FADS1, fatty acid desaturase 1; FAME, fatty acid methyl esters; FASN, fatty acid synthase; HOMA-IR, homoeostasis model assessment using the insulin resistance index; IMF, intramuscular fat; NPD, normal protein diet; PC, principal component; RPD, reduced protein diet; SCD, stearoyl-CoA desaturase; SREBF1, sterol regulatory element-binding factor 1.
}

* Corresponding author: J. A. M. Prates, fax +351 213652 895, email japrates@fmv.ulisboa.pt

$\dagger$ Both authors contributed equally to this work. 
Acetyl-CoA carboxylase $\alpha$ (ACACA), fatty acid synthase (FASN) and stearoyl-COA desaturase (SCD or delta9 desaturase) are key lipogenic enzymes for fatty acid biosynthesis. Attending to the paramount role of liver in fatty acid elongation and desaturation, fatty acid desaturase 1 (FADS1, encoding for delta5 desaturase) and fatty acid desaturase 2 (FADS2, encoding for delta6 desaturase) are membrane-bound enzymes that catalyse the synthesis of PUFA ${ }^{(12)}$. Moreover, carnitine $O$ acetyltransferase (CRAT) is the rate-limiting enzyme of lipid catabolism, transporting fatty acid esters to the mitochondria for $\beta$-oxidation. The transcriptional regulators, SREBF, carbohydrate response element-binding protein (ChREBP), CCAAT/ enhancer-binding protein $\alpha$ and PPAR appear to be the main enzymes responsible for hepatic fatty acid synthesis and degradation, and subsequent TAG production ${ }^{(13)}$. In addition, glucose and insulin play a critical role in transcriptional and post-transcriptional regulation of lipogenesis, through the activation of hepatic ChREBP and SREBF1C genes, respectively ${ }^{(14)}$. The fatty acid binding protein 4 (FABP4) is accountable for fatty acid transport in adipocytes ${ }^{(15)}$

We have previously shown that the molecular mechanisms regulating fat deposition in skeletal muscle and subcutaneous adipose tissue in pigs are tissue specific and genotype specific, and linked to the differential expression of genes encoding for lipogenic enzymes and transcription factors ${ }^{(5)}$. In the present study, we question the effect of RPD under different genotypes (commercial cross-bred lean pigs $v$. autochthonous fatty pigs) on hepatic lipid metabolism, through the assessment of fatty acid profile and gene expression levels of key lipogenic enzymes and associated transcription factors.

\section{Methods}

\section{Animals and experimental diets}

This trial was conducted at the facilities of Unidade de Investigação em Produção Animal (Instituto de Investigação Agrária e Veterinária, UIPA-INIAV). All the experimental procedures involving animals were reviewed by the Ethics Commission of the CIISA/FMV and approved by the Animal Care Committee of the National Veterinary Authority (Direção-Geral de Alimentação e Veterinária, Portugal), following the appropriate European Union guidelines (2010/63/EU Directive). In all, twenty commercial cross-bred pigs (50\% Large White, $25 \%$ Landrace and $25 \%$ Pietrain) and twenty Alentejana purebred pigs, all entire males, were selected, with an average initial body weight of 60 (sD 2) kg. The Alentejano pig is a Portuguese autochthonous breed reared in the southern region of Portugal and is genetically similar to the Spanish Iberian breed with low capacity for lean tissue deposition ${ }^{(16)}$. Moreover, this breed is characterised for having slow growth and high feed conversion ratio as well as high fat deposition. At present, there is a growing interest in high-quality products from the Alentejana pig from both producers and consumers ${ }^{(17)}$. Pigs were fed a standard concentrate diet from weaning until the beginning of the experiment. Animals were housed in two pens of four pigs each and one pen of two pigs per treatment ( $n$ 10). Pigs were fed individually twice a day and had free access to water.
Throughout the experiment, pigs were weighted weekly just before feeding. Pigs from each genotype were randomly assigned to one of two diets in a $2 \times 2$ factorial arrangement (two genotypes and two dietary regimens).

Diets were isoenergetically formulated (16 MJ metabolisable energy $/ \mathrm{kg}$ ) and differed in crude protein and lysine contents: $17.5 \%$ of crude protein and $0.7 \%$ of lysine (normal protein diet, NPD) and $13.1 \%$ of crude protein and $0.4 \%$ of lysine (RPD not equilibrated for lysine, RPD). Diets were analysed for DM by drying samples $(n 4)$ at $100^{\circ} \mathrm{C}$ to a constant weight. $\mathrm{N}$ content was determined by the Kjeldahl method ${ }^{(18)}$ and crude protein was calculated as $6 \cdot 25 \times \mathrm{N}$. Crude fibre was determined by the procedure described by the Association of Official Analytical Chemists $(\mathrm{AOAC})^{(18)}$. Samples were extracted with petroleum diethyl ether, using an automatic Soxhlet extractor (Gerhardt Analytical Systems) to determine crude fat. Determination of ash and starch contents was carried out according to the procedures described in $\mathrm{AOAC}^{(18)}$ and in the study by Clegg ${ }^{(19)}$, respectively. Gross energy in the feed was determined by adiabatic bomb calorimetry (Parr 1261; Parr Instrument Company). Fatty acid methyl esters (FAME) of feed samples were analysed by one-step extraction and transesterification, using heptadecaenoic acid $(17: 0)$ as the internal standard ${ }^{(20)}$. Total amino acids were extracted according to the method described by $\mathrm{AOAC}^{(21)}$. The extract was analysed by HPLC (Agilent 1100; Agilent Technologies) to quantify amino acids in the feed, including lysine, according to the procedure reported by Henderson $e t a l .{ }^{(22)}$. The ingredients and detailed proximate and fatty acid composition of the diets are shown in Table 1.

\section{Slaughter and sampling}

Pigs were slaughtered at an average body weight of 93.4 (SD 2.42) $\mathrm{kg}$ at the INIAV experimental abattoir, after $17-19 \mathrm{~h}$ of fasting. After electrical stunning and exsanguination, blood samples were collected from the jugular vein and centrifuged at $1500 \boldsymbol{g}$ for $15 \mathrm{~min}$ to obtain plasma. Samples for gene expression analysis were collected from the middle lobe of the liver, rinsed with sterile RNAse-free cold saline solution, cut into small pieces (thickness of approximately $0 \cdot 3 \mathrm{~cm}$ ), stabilised in RNA Later $^{\circledR}$ solution (Qiagen) and stored at $-80^{\circ} \mathrm{C}$. For fatty acid composition, liver samples were vacuum-packed and stored at $-20^{\circ} \mathrm{C}$ until analysis.

\section{Plasma metabolites}

Total cholesterol, HDL-cholesterol, LDL-cholesterol, TAG, phospholipids, total proteins, urea, $\mathrm{N}$ and glucose concentrations, aspartate aminotransferase, alanine aminotransferase (ALT), $\gamma$-glutamyltransferase (GGT) and alkaline phosphatase (ALP) were analysed using diagnostic kits (Roche Diagnostics) and a Modular Hitachi Analytical System (Roche Diagnostics). VLDL-cholesterol and total lipids were calculated as described by Friedewald et $a l^{(23)}$ and Covaci et $a l^{(24)}$, respectively. Free fatty acids (FFA) were quantified using the Free Fatty Acid Quantification Kit (BioVision Inc.). Insulin and leptin concentrations were determined through the Porcine Insulin RIA kit (PI-12K; Linco Research) and the Multi-Species Leptin RIA kit (XL-85K; 
Table 1. Diet formulation and chemical composition of experimental diets $(n 4)^{\star}$

\begin{tabular}{|c|c|c|}
\hline & NPD & RPD \\
\hline \multicolumn{3}{|l|}{ Diet formulation (\%) } \\
\hline Barley & 40.00 & 50.00 \\
\hline Wheat & $26 \cdot 12$ & 29.02 \\
\hline Soyabean meal & 24.78 & 11.79 \\
\hline Maize & 5.00 & 5.00 \\
\hline Soyabean oil & 1.58 & 1.54 \\
\hline Calcium carbonate & 1.14 & 1.13 \\
\hline Salt & 0.39 & 0.39 \\
\hline Di-calcium phosphate & 0.23 & 0.38 \\
\hline \multicolumn{3}{|c|}{ Chemical composition (\% diet) } \\
\hline DM & $89 \cdot 1$ & $89 \cdot 0$ \\
\hline Crude protein & $17 \cdot 5$ & $13 \cdot 1$ \\
\hline Starch & $47 \cdot 2$ & $55 \cdot 2$ \\
\hline Crude fat & 3.1 & $2 \cdot 9$ \\
\hline Crude fibre & 4.9 & 4.0 \\
\hline Ash & 4.4 & 4.0 \\
\hline L-Lys & 0.7 & 0.4 \\
\hline $\mathrm{Ca}$ & 0.82 & 0.84 \\
\hline $\mathrm{P}$ & 0.37 & 0.37 \\
\hline ME (MJ ME/kg) & $13 \cdot 3$ & 13.5 \\
\hline \multicolumn{3}{|c|}{ Fatty acid composition (\% total fatty acids) } \\
\hline $14: 0$ & 0.1 & 0.2 \\
\hline $16: 0$ & $17 \cdot 3$ & $19 \cdot 6$ \\
\hline $16: 1 c 9$ & 0.8 & 0.2 \\
\hline $18: 0$ & $2 \cdot 6$ & 2.6 \\
\hline $18: 1 c 9$ & $19 \cdot 0$ & $19 \cdot 3$ \\
\hline $18: 1 c 11$ & 1.5 & 1.6 \\
\hline $18: 2 n-6$ & 52.5 & $50 \cdot 2$ \\
\hline $18: 3 n-3$ & 4.9 & $4 \cdot 3$ \\
\hline $20: 0$ & 0.3 & 0.3 \\
\hline $20: 1 c 11$ & 0.4 & 0.5 \\
\hline \multicolumn{3}{|c|}{ Amino acid composition (\% diet) } \\
\hline Ala & 0.91 & 0.65 \\
\hline Arg & 1.32 & 0.88 \\
\hline Asp & $2 \cdot 06$ & 1.36 \\
\hline Glu & 4.62 & 3.68 \\
\hline Gly & 0.82 & 0.55 \\
\hline His & 0.51 & 0.35 \\
\hline Iso & 0.86 & 0.60 \\
\hline Leu & 1.58 & $1 \cdot 14$ \\
\hline Lys & 0.65 & 0.40 \\
\hline Met & 0.12 & 0.10 \\
\hline Phe & 1.07 & 0.78 \\
\hline Pro & 1.42 & 1.21 \\
\hline Ser & 1.00 & 0.70 \\
\hline Tau & 0.01 & 0.01 \\
\hline Thr & 0.94 & 0.64 \\
\hline Tyr & 0.65 & 0.46 \\
\hline Val & 1.02 & 0.77 \\
\hline
\end{tabular}

NPD, normal protein diet; RPD, reduced protein diet; ME, metabolisable energy

* Others ingredients in both diets: pigs vitatec $(0.4 \%)$, tecaphos $500 \mathrm{~g}(0.1 \%)$, ultracid V Dry EU $(0.1 \%)$, grain Tec TS $(0.1 \%)$, unilike Plus Dry $(0.05 \%)$, oxi-Nil Dry Premix $(0.003 \%)$.

Linco Research), respectively. The degree of insulin resistance was calculated by the homoeostasis model assessment using the insulin resistance index (HOMA-IR): fasting serum glucose ( $\mathrm{mmol} / \mathrm{l})$ times fasting serum insulin $(\mathrm{mU} / \mathrm{l})$ divided by $22 \cdot 5^{(25)}$. Low HOMA-IR values indicate high insulin sensitivity, whereas high HOMA-IR values indicate high insulin resistance.

\section{Hepatic lipid extraction and fatty acid composition}

Liver samples were lyophilised $\left(-60^{\circ} \mathrm{C}\right.$ and $\left.2 \cdot 0 \mathrm{hPa}\right)$, maintained exsiccated at room temperature and analysed within 2 weeks.
Total lipids were extracted in duplicate and gravimetrically measured by the method described by Folch et al. ${ }^{(26)}$, using dichloromethane-methanol $(2: 1, \mathrm{v} / \mathrm{v})$ instead of chloroformmethanol $(2: 1, \mathrm{v} / \mathrm{v})$, as described by Carlson ${ }^{(27)}$. Fatty acids were converted to methyl esters (FAME) by combined transesterification procedure with $\mathrm{NaOH}$ in anhydrous methanol $(0.5 \mathrm{M})$, followed by $\mathrm{HCl}-$ methanol $(1: 1, \mathrm{v} / \mathrm{v})$, at $50^{\circ} \mathrm{C}$ during 30 and $10 \mathrm{~min}$, respectively, according to Raes et al. $^{(28)}$. FAME were determined using a GC HP6890A (Hewlett-Packard), equipped with a flame ionisation detector and a CP-Sil 88 capillary column $(100 \mathrm{~m} \times 0.25 \mathrm{~mm}$ i.d., $0 \cdot 20-\mu \mathrm{m}$ film thickness; Chrompack, Varian Inc.) using the conditions described in Alves \& Bessa ${ }^{(29)}$. The quantification of total FAME was carried out using nonadecanoic acid methyl ester (19:0) as the internal standard and by the conversion of relative peak areas into weight percentages. Fatty acids were identified on the basis of their retention times, corresponding to their FAME standards from Supelco Inc. and expressed as $\mathrm{g} / 100 \mathrm{~g}$ of total fatty acids.

\section{Hepatic RNA isolation and complementary DNA synthesis}

Total RNA was isolated and purified from the liver using a modified protocol combining Trizol (Invitrogen) and RNeasy mini kit (Qiagen), respectively. Before real-time quantitative PCR (RT-qPCR), total RNA samples were treated with DNAse I (Qiagen). All the procedures were performed in accordance with the manufacturer's protocols. RNA was quantified using a NanoDrop ND-2000c spectrophotometer (Nanodrop; Thermo Fisher Scientific). The A260/280 ratios were between 1.9 and $2 \cdot 1$. Reverse transcription was performed with a High-Capacity cDNA Reverse Transcription Kit (Applied Biosystems). In brief, each $20 \mu \mathrm{l}$ RT reaction contained $1 \mu \mathrm{g}$ of DNase-treated total RNA template, $50 \mathrm{~nm}$ random RT Primer, $1 \times \mathrm{RT}$ buffer, $0.25 \mathrm{~mm}$ of each dNTP, $3.33 \mathrm{U} / \mu \mathrm{l}$ multiscribe RT and $0.25 \mathrm{U} / \mu \mathrm{l}$ RNase inhibitor, and was subjected to heating at $25^{\circ} \mathrm{C}$ for $10 \mathrm{~min}, 37^{\circ} \mathrm{C}$ for $120 \mathrm{~min}$ and $85^{\circ} \mathrm{C}$ for $5 \mathrm{~min}$. The complementary DNA (cDNA) solution obtained was divided into aliquots and stored at $-20^{\circ} \mathrm{C}$ until further analysis.

\section{Real-time quantitative PCR}

Gene-specific intron-spanning primers were designed using Primer3 (http://frodo/wi.mit.edu/primer3/) and Primer Express Software version 2.0 (Applied Biosystems) based on Sus scrofa sequences (www.ncbi.nlm.nih.gov). Primers were purchased from NZYTech. Sequence homology searches against the database of GenBank showed that these primers matched only the sequence to which they were designed. To ensure optimal DNA polymerisation efficiency, the amplicon length ranged between 71 and $138 \mathrm{bp}$. Before performing qPCR assays, a conventional PCR was carried out for all genes in order to test the primers and verify the amplified products. To confirm identity of amplified fragments, PCR products were sequenced and homology searches were performed with Blast (www.ncbi. nlm.nih.gov/blast). In order to find the most stable endogenous control in the liver, five commonly used housekeeping genes, glyceraldehyde-3-phosphate dehydrogenase, 60S ribosomal protein L27 (RPL27), ornithine decarboxylase antizyme 1, 
ribosomal protein large $\mathrm{P} 0(R P L P 0)$ and $40 \mathrm{~S}$ ribosomal protein S29 (RPS29) were used to normalise the results of target genes. The stability of the expression levels of housekeeping genes was analysed using geNorm ${ }^{(30)}$ and NormFinder ${ }^{(31)}$ software packages, as described in their manuals. The RPLPO and RPL27 genes were selected as the most stable internal pair of controls for normalisation. The information regarding sequence of primers (including annealing temperatures), GenBank accession numbers, PCR efficiency, regression coefficient and span exons for PCR products is provided in Table 2 .

PCR efficiency was calculated for each amplicon using StepOnePlus PCR System software (Applied Biosystems), by amplifying 5-fold serial dilutions of pooled cDNA and run in triplicate. All primer sets exhibited an efficiency ranging from 90 to $110 \%$ and correlation coefficients were higher than 0.99 . RT-qPCR reactions were carried out using MicroAmp Optical ninety-six-well plates (Applied Biosystems) in a StepOnePlus thermocycler (Applied Biosystems) in standard cycling conditions. The $12 \cdot 5-\mu \mathrm{l}$ PCR reaction mixture contained $6 \cdot 25 \mu \mathrm{l}$ of $2 \times$ Power SYBR Green PCR Master Mix (Applied Biosystems), $160 \mathrm{~nm}$ of forward and reverse primers and $2 \mu \mathrm{l}$ of diluted cDNA as template. No transcription and no template samples were used as controls. The primer specificity and the formation of primer-dimers were confirmed by melt curve analysis and agarose gel electrophoresis. All the analyses were performed in duplicate, and the relative amounts for each target gene were calculated using the geometric mean of RPLPO/RPL27 as normaliser. The relative expression levels were calculated as a variation of the Livak method ${ }^{(32)}$, corrected for variation in amplification efficiency, as described by Fleige et al. ${ }^{(33)}$.

\section{Statistical analysis}

All data were checked for normality and variance homogeneity. As variance heterogeneity was detected for most of the variables, data were analysed using the Proc MIXED of SAS software package ${ }^{(34)}$ (version 9.2; SAS Institute). The statistical model included genotype, diet and their respective interaction, as fixed effects, and the repeated statement considering the group option to accommodate the variance heterogeneity. The level of significance was set at $P<0 \cdot 05$. The need for covariate adjustment was exploited using hepatic total lipids. Whenever a covariate for each variable was needed, the structure of the covariate model was determined according to the procedures described by Milliken \& Johnson ${ }^{(35)}$ and ranged from a simple slope model to individual slopes for each diet $\times$ genotype combination. The adjusted variables and their covariance models are identified in the footnotes of tables. As large differences in covariate ranges were intrinsically associated with each genotype, the variable was adjusted and compared with the mean covariate value of each genotype ${ }^{(35)}$. When significant effects were detected, least square means (LSMEANS) were determined using the LSMEANS option and compared using the probability difference procedure adjusted for multiple comparisons, using the Tukey-Kramer method.

Pearson's correlation coefficients were calculated using the PROC CORR procedure of SAS. A principal component analysis (PCA) was performed with individual fatty acids from the liver. The PRINCOMP procedure was applied to a data set of twentyfour samples and thirty-three variables to reduce the dimensionality of the data set and to describe the variability of data into two dimensions. After data normalisation, the principal components (PC) were considered significant if they contributed to $>5 \%$ of the total variance.

\section{Results}

\section{Growth performance parameters}

Data on growth performance parameters in lean and fatty pigs fed NPD or RPD are shown in Table 3. Fatty pigs had a higher average daily feed intake (ADFI) compared with lean pigs $(P<0 \cdot 001)$. The inverse was found for gain:feed $(\mathrm{G}: \mathrm{F})$

Table 2. Characterisation of the select genes used in the real-time quantitative PCR assay

\begin{tabular}{|c|c|c|c|c|c|}
\hline & Full gene name & $\begin{array}{l}\text { GenBank accession } \\
\text { number }\end{array}$ & Forward primer & Reverse primer & $\begin{array}{l}\text { Product } \\
\text { size (bp) }\end{array}$ \\
\hline \multicolumn{6}{|c|}{ Gene symbol } \\
\hline ACACA & Acetyl-CoA carboxylase $a$ & NM_001114269 & ggccatcaaggacttcaacc & acgatgtaagcgccgaactt & 120 \\
\hline CEBPA & $\begin{array}{l}\text { CCAAT/enhancer-binding protein } \\
\text { (C/EBP) } a\end{array}$ & XM_003127015 & ggccagcacacacacattaga & cccccaaagaagagaaccaag & 71 \\
\hline ChREBP & $\begin{array}{l}\text { Carbohydrate response element-binding } \\
\text { protein }\end{array}$ & XM_003481002 & tgacatgatccagcctgacc & gggggctcagagaagtttga & 126 \\
\hline CRAT & Carnitine $O$-acetyltransferase & NM_001113047 & ggcccaccgagcctacac & atggcgatggcgtaggag & 138 \\
\hline FADS1 & Fatty acid desaturase 1 & NM_001113041.1 & ccactgttggggctgaagg & gatgtgcatggggatgtggt & 108 \\
\hline FADS2 & Fatty acid desaturase 2 & NM_001171750.1 & gccttacaaccaccagcatga & aggccaagtccacccagtc & 122 \\
\hline FABP4 & Fatty acid binding protein 4 & NM_001002817 & gggccaggaatttgatgaag & ctttccatcccacttctgcac & 103 \\
\hline FASN & Fatty acid synthase & NM_001099930 & acaccttcgtgctggectac & atgtcggtgaactgctgcac & 112 \\
\hline PPARA & PPARa & NM_001044526 & tttccctctttgtggctget & ggggtggttggtctgcaag & 128 \\
\hline$S C D$ & Stearoyl-CoA desaturase & NM_213781 & agccgagaagctggtgatgt & gaagaaaggtggcgacgaac & 140 \\
\hline SREBF1 & $\begin{array}{l}\text { Sterol regulatory element-binding } \\
\text { factor } 1\end{array}$ & NM_214157 & gtgctggcggaggtctatgt & aggaagaagcgggtcagaaag & 96 \\
\hline \multicolumn{6}{|c|}{$\begin{array}{l}\text { Housekeeping } \\
\text { genes }\end{array}$} \\
\hline RPLPO & Ribosomal phosphoprotein large, P0 subunit & NM_001098598 & tccaggctttaggcatcacc & ggctcccactttgtctccag & 95 \\
\hline RPL27 & Ribosomal protein L27 & NM_001001633 & ggtcagggttctcgctcttg & cactggcggcacatattgag & 120 \\
\hline
\end{tabular}


Table 3. Effect of the reduced protein diet (RPD) on growth performance variables and plasma biochemical metabolites in lean and fatty pigs (Mean values with their standard errors)

\begin{tabular}{|c|c|c|c|c|c|c|c|c|c|c|c|}
\hline & \multicolumn{4}{|c|}{ Lean } & \multicolumn{4}{|c|}{ Fatty } & & & \\
\hline & \multicolumn{2}{|c|}{ NPD } & \multicolumn{2}{|c|}{ RPD } & \multicolumn{2}{|c|}{ NPD } & \multicolumn{2}{|c|}{ RPD } & \multicolumn{3}{|c|}{ Significance level } \\
\hline & Mean & SE & Mean & $\mathrm{SE}$ & Mean & SE & Mean & SE & Genotype & Diet & Genotype $\times$ Diet \\
\hline \multicolumn{12}{|l|}{ Growth performance } \\
\hline ADFI $(k g)$ & 2.49 & 0.091 & 2.67 & 0.095 & 3.07 & 0.096 & 3.39 & 0.106 & $<0.001$ & 0.010 & 0.586 \\
\hline ADG $(g)$ & 848 & 37 & 747 & 23 & 809 & 39 & 806 & 24 & 0.753 & 0.110 & 0.126 \\
\hline $\mathrm{G}: \mathrm{F}(\mathrm{kg} / \mathrm{kg})$ & 0.34 & 0.011 & 0.28 & 0.007 & 0.26 & 0.007 & 0.24 & 0.008 & $<0.001$ & $<0.001$ & 0.024 \\
\hline \multicolumn{12}{|l|}{ Plasma lipids } \\
\hline Total lipids (mg/l) & 3687 & $70 \cdot 2$ & 3808 & $67 \cdot 4$ & 3086 & 236 & 3124 & 157 & $<0.001$ & 0.603 & 0.785 \\
\hline $\mathrm{TAG}(\mathrm{mg} / \mathrm{l})$ & 311 & 17.0 & 381 & $30 \cdot 1$ & 336 & 21.5 & 388 & 17.9 & 0.487 & 0.011 & 0.696 \\
\hline Phospholipids (mg/l) & 1130 & 2.91 & 1160 & 2.74 & 1050 & 4.16 & 1030 & 2.46 & 0.002 & 0.803 & 0.627 \\
\hline Free fatty acids $(\mu \mathrm{mol} / \mathrm{l})$ & 53.4 & $16 \cdot 69$ & $95 \cdot 2$ & $19 \cdot 73$ & 35.9 & 4.89 & 68.0 & $17 \cdot 01$ & 0.165 & 0.026 & 0.758 \\
\hline Total cholesterol $(\mathrm{mg} / \mathrm{l})$ & 937 & $32 \cdot 3$ & 963 & 30.7 & 830 & $47 \cdot 3$ & 826 & $28 \cdot 3$ & 0.002 & 0.763 & 0.680 \\
\hline HDL-cholesterol (mg/l) & 287 & 11.4 & 304 & 13.0 & 319 & $16 \cdot 1$ & 365 & $28 \cdot 6$ & 0.021 & 0.100 & 0.454 \\
\hline LDL-cholesterol (mg/l) & 588 & 24.9 & 582 & $23 \cdot 1$ & 399 & $61 \cdot 1$ & 383 & $24 \cdot 6$ & $<0.001$ & 0.766 & 0.894 \\
\hline VLDL-cholesterol (mg/l) & $62 \cdot 2$ & 3.41 & $76 \cdot 2$ & 6.01 & 60.4 & 7.73 & $77 \cdot 6$ & 3.59 & 0.968 & 0.009 & 0.773 \\
\hline \multicolumn{12}{|l|}{ Other plasma metabolites } \\
\hline Glucose $(\mathrm{mg} / \mathrm{l})$ & 1260 & 153 & 1170 & $40 \cdot 3$ & 1170 & 108 & 1010 & 39 & 0.254 & 0.225 & 0.755 \\
\hline Insulin (mU/l) & 4.36 & 0.303 & 4.90 & 0.525 & 7.49 & 1.552 & 9.69 & 1.954 & 0.006 & 0.299 & 0.525 \\
\hline HOMA-IR $(\mathrm{mmol} / \mathrm{l} \mu \mathrm{U} / \mathrm{ml})^{*}$ & $2 \cdot 16$ & 0.459 & 2.51 & 0.542 & 2.93 & 1.151 & 1.36 & 0.192 & 0.784 & 0.388 & 0.179 \\
\hline Leptin $(\mu \mathrm{g} / \mathrm{l})$ & 1.94 & 0.287 & 2.51 & 0.314 & 6.37 & 0.946 & 5.90 & 0.875 & $<0.001$ & 0.942 & 0.454 \\
\hline Urea $(\mathrm{mg} / \mathrm{l})$ & 278 & $16 \cdot 9$ & 233 & 11.9 & 380 & 24.6 & 295 & $15 \cdot 8$ & $<0.001$ & 0.001 & 0.268 \\
\hline Total protein $(\mathrm{g} / \mathrm{l})$ & $74 \cdot 1^{\mathrm{b}}$ & 1.56 & $67.9^{\mathrm{a}}$ & 1.59 & $75 \cdot 9^{\mathrm{b}, \mathrm{c}}$ & 1.60 & $78 \cdot 8^{\mathrm{c}}$ & 0.99 & $<0.001$ & 0.266 & 0.004 \\
\hline \multicolumn{12}{|l|}{ Plasma hepatic markers } \\
\hline ALT (U/I) & 29.6 & 1.94 & 33.0 & 1.38 & $36 \cdot 1$ & 3.01 & $36 \cdot 3$ & 2.44 & 0.040 & 0.432 & 0.481 \\
\hline AST (U/I) & $45 \cdot 1$ & 3.08 & 58.6 & $7 \cdot 29$ & 54.8 & 7.44 & $60 \cdot 4$ & 5.96 & 0.361 & 0.136 & 0.533 \\
\hline ALP (U/I) & 156 & 8.09 & 176 & 11.7 & 84.0 & $6 \cdot 18$ & 85.3 & 7.82 & $<0.001$ & 0.231 & 0.291 \\
\hline GGT (U/I) & $26 \cdot 8$ & 4.35 & 25.4 & 2.89 & $50 \cdot 7$ & 7.62 & $51 \cdot 2$ & 3.93 & $<0.001$ & 0.937 & 0.854 \\
\hline
\end{tabular}

Lean, commercial cross-bred pigs ( $50 \%$ Large White, $25 \%$ Landrace and $25 \%$ Pietrain); fatty, Alentejana purebred pigs; NPD, normal protein diet; ADFI, average daily feed intake; ADG, average daily gain; G:F, gain:feed; HOMA-IR, homoeostasis model assessment using the insulin resistance index; ALT, alanine aminotransferase (EC 2.6.1.2); AST, aspartate aminotransferase (EC 2.6.1.1); ALP, alkaline phosphatase (EC 3.1.3.1); GGT, $\gamma$-glutamyltransferase (EC 2.3.2.13).

a,b,c Mean values within a row with unlike superscript letters were significantly different $(P<0.05)$.

* HOMA-IR, insulin resistance index $=$ (fasting plasma glucose) $\times$ (fasting plasma insulin) $/ 22.5$ 
$(P<0.001)$. The RPD, relative to NPD, increased ADFI $(P=0.010)$ but decreased $\mathrm{G}: \mathrm{F}(P<0.001)$. The average daily gain (ADG) was not affected by genotype or by diet $(P>0.05)$.

\section{Plasma biochemical profile}

The plasma metabolites are presented in Table 3. The lipid profile was extensively influenced (five out of eight) by genotype. Total lipids $(P<0 \cdot 001)$, phospholipids $(P=0 \cdot 002)$, total cholesterol $(P=0.002)$ and LDL-cholesterol $(P<0.001)$ levels were higher in lean than in fatty pigs, in contrast to HDL-cholesterol $(P=0.021)$. Diet only influenced three out of the eight plasma lipids assessed. In fact, the RPD, relative to the NPD, increased TAG $(P=0.011)$, FFA $(P=0.026)$ and VLDL-cholesterol $(P=0 \cdot 009)$.

Insulin and leptin were affected by genotype, but not by diet, with higher contents in fatty pigs when compared with lean ones $(P=0.006$ and $P<0.001$ for insulin and leptin, respectively). Glucose and HOMA-IR were unchanged across experimental groups $(P>0 \cdot 05)$. Urea levels were lower in both lean pigs $(P<0.001)$ and pigs fed $\operatorname{RPD}(P=0.001)$. In addition, a significant interaction between genotype and diet was observed for total protein $(P=0.004)$, with lower values in lean pigs fed RPD.

Regarding the hepatic enzymes, fatty pigs had higher levels of ALT $(P=0.040)$ and GGT $(P<0.001)$ and lower levels of ALP $(P<0.001)$ compared with lean pigs. No influence of diet was found for any of these hepatic markers $(P>0 \cdot 05)$.

\section{Hepatic total lipids and fatty acid composition}

The hepatic lipid content and composition are presented in Table 4. Concerning total lipid content, a genotype effect $(P=0.049)$ was observed, with higher values in the fatty genotype, without influence of dietary treatment.

The predominant fatty acids found across experimental groups were $18: 0$ (28-31\%), 18:2n-6 (15-20\%), 16:0 (15-16\%), 20:4n-6 (11-14\%) and 18:1c9 (11-13\% of total FAME). The genotype affected thirteen out of the twenty-seven fatty acids identified. The proportions of $16: 1 c 7(P<0.001)$, $18: 1 c 11 \quad(P<0.001), 14: 0 \quad(P=0.001), 16: 1 c 9 \quad(P=0.001)$, $20: 6 n-3 \quad(P=0 \cdot 001), \quad 18: 3 n-6 \quad(P=0 \cdot 017)$ and $20: 5 n-3$ $(P=0 \cdot 047)$ were higher in lean pigs, when compared with fatty ones. In contrast, the percentages of $18: 2 n-6 \quad(P<0 \cdot 001)$, 20:2n-6 ( $P<0.001), 20: 3 n-6(P<0.001), 20: 3 n-3$ ( $P=0.001)$, $20: 3 n-9(P=0.002)$ and $23: 0(P=0.004)$ were higher in fatty than in lean pigs. The RPD affected six individual fatty acids. The proportions of $14: 0 \quad(P=0.009), 18: 1 c 11 \quad(P=0.009)$, $20: 1 c 11(P=0.009), 16: 1 c 9(P=0.030)$ and $18: 1 c 9(P=0.032)$ were higher in pigs fed RPD when compared with pigs fed NPD, in contrast with the proportion of 20:0 $(P=0 \cdot 014)$. A significant interaction between genotype and diet was observed for $18: 1 t(P=0.032)$, with lower values of this minor fatty acid $(<0.3 \%$ of total fatty acids) in fatty pigs fed NPD.

Regarding fatty acid sums and ratios (Table 4), the differences observed reflected the variations described earlier for the major individual fatty acids. The genotype influenced both $n-6: n-3$ ratio $(P<0.001)$ and $n-6$ PUFA sum $(P=0.046)$, with higher values found in fatty pigs. The proportion of MUFA $(P=0.019)$ was increased by RPD when compared with NPD.

\section{Principal component analysis}

A PCA using hepatic fatty acid composition was performed to describe variability of the pooled data into two dimensions (Fig. 1(a)). The score plot of the first two PC explained $51.9 \%$ of the total variability, with $33.7 \%$ for PC1 and $18.2 \%$ for PC2 (Table 5).

The PC1 was characterised by variables with positive loadings, such as $14: 0,18: 1 c 11,18: 1 c 9,16: 1 c 9,16: 1 c 7,18: 1 t$, $18: 0,16: 0$ and $20: 1 c 11$, and by variables with negative loadings, such as $18: 2 n-6,22: 5 n-3,20: 3 n-3,20: 2 n-6,22$ : $4 n-6,20: 3 n-6,20: 4 n-6,20: 3 n-9,20: 0,22: 0,18: 3 n-3,20$ : $5 n-3$ and $22: 6 n-3$ (Table 5). Concerning the PC2, all variables had small contributions with loadings varying between -0.5 and 0.5 . The score plot depicted in Fig. 1(b) shows the location of the four experimental groups, lean and fatty pigs fed NPD and $\mathrm{RPD}$, in the multivariate space of the first two PC. These scores were notably arranged in one cluster, corresponding to fatty pigs. The fatty genotype was located mainly in quadrant $d$, whereas the lean genotype was dispersed across quadrants $a$ and $c$. The discrimination of dietary treatments was unattainable.

\section{Gene expression levels of key lipogenic enzymes and associated transcription factors in the liver}

The expression levels of key genes controlling lipid metabolism in the liver are presented in Fig. 2. Relative ACACA $(P<0 \cdot 001)$, $F A S N(P<0 \cdot 001), S C D(P<0 \cdot 001)$, sterol regulatory elementbinding factor $1(S R E B F 1)(P<0.001)$ and CRAT $(P=0.006)$ mRNA levels were higher in fatty pigs when compared with lean pigs. In addition, the expression levels of genes were not affected by dietary treatments, except for SREBF1 $(P=0.023)$, with lower values in pigs fed RPD. An interaction between genotype and diet was observed for both FADS1 $(P=0.031)$ and FABP4 $(P=0.032)$ mRNA levels. The RPD increased FADS1 and $F A B P 4$ expression levels in lean and fatty pigs, respectively.

\section{Correlation between hepatic fatty acid composition and gene expression levels}

The correlation coefficients $(r)$ between fatty acids and gene expression levels in the liver, adjusted for total lipids as covariate, are shown in Table 6 . The genes involved in lipogenesis, such as FADS1, FADS2 and FASN, were the most correlated with fatty acid composition, along with SCD, SREBF1 and ACACA.

FADS1 mRNA levels were negatively correlated with $18: 2 n-6$ $(P<0 \cdot 001), 20: 2 n-6 \quad(P<0 \cdot 001), 20: 3 n-6 \quad(P<0 \cdot 001), 20:$ 3n-3 $(P<0.001), 23: 0(P<0 \cdot 01), 20: 0(P<0.05)$ and $20: 3 n-9$ $(P<0.05)$, but positively correlated with $14: 0 \quad(P<0.001)$, $16: 1 c 9(P<0.01)$ and 18:3n-6 $(P<0.05)$. FADS2 mRNA levels were correlated with the same fatty acids as FADS1, and also positively correlated with $18: 1 t(P<0 \cdot 001)$. The expression levels of $F A S N$ gene showed moderate $(0.3>r<0.7)$ negative correlations with $16: 1 c 7(P<0 \cdot 001), 18: 1 t(P<0 \cdot 001), 18: 1 c 11$ 
Neritish Journal of Nutrition

Table 4 . Effect of the reduced protein diet (RPD) on total lipids ( $\mathrm{g} / 100 \mathrm{~g}$ liver), fatty acid composition (\% total fatty acids), partial sums of fatty acids and related ratios in the liver of lean and fatty pigs (Mean values with their standard errors)

\begin{tabular}{|c|c|c|c|c|c|c|c|c|c|c|c|}
\hline & \multicolumn{4}{|c|}{ Lean } & \multicolumn{4}{|c|}{ Fatty } & & & \\
\hline & \multicolumn{2}{|c|}{ NPD } & \multicolumn{2}{|c|}{ RPD } & \multicolumn{2}{|c|}{ NPD } & \multicolumn{2}{|c|}{ RPD } & \multicolumn{3}{|c|}{ Significance level } \\
\hline & Mean & SE & Mean & SE & Mean & SE & Mean & SE & G & D & $G \times D$ \\
\hline \multicolumn{10}{|l|}{ Fatty acid composition } & & \\
\hline $14: 0$ & 0.53 & 0.049 & 0.72 & 0.062 & 0.41 & 0.029 & 0.49 & 0.049 & 0.001 & 0.009 & 0.284 \\
\hline $15: 0$ & 0.11 & 0.009 & 0.11 & 0.018 & 0.10 & 0.008 & 0.08 & 0.008 & 0.258 & 0.509 & 0.324 \\
\hline $16: 0$ & $15 \cdot 1$ & 0.58 & $15 \cdot 5$ & 0.810 & 15.9 & 0.73 & 15.8 & 0.624 & 0.425 & 0.922 & 0.693 \\
\hline $16: 1 c 7^{\star}$ & 0.32 & 0.015 & 0.35 & 0.020 & 0.22 & 0.019 & 0.26 & 0.024 & $<0.001$ & 0.073 & 0.696 \\
\hline $16: 1 c 9^{*}$ & 0.63 & 0.033 & 0.79 & 0.061 & 0.52 & 0.030 & 0.56 & 0.050 & 0.001 & 0.030 & 0.162 \\
\hline $17: 0^{*}$ & 0.94 & 0.084 & 0.98 & 0.162 & 1.15 & 0.121 & 0.99 & 0.058 & 0.349 & 0.590 & 0.381 \\
\hline $17: 1 c 9$ & 0.18 & 0.013 & 0.22 & 0.032 & 0.18 & 0.015 & 0.16 & 0.009 & 0.099 & 0.613 & 0.124 \\
\hline $18: 0$ & 30.6 & 1.46 & $29 \cdot 6$ & 1.194 & $28 \cdot 2$ & 0.63 & 28.5 & 0.924 & 0.115 & 0.759 & 0.542 \\
\hline $18: 1 t$ & $0.22^{b, c}$ & 0.021 & $0.27^{c}$ & 0.023 & $0 \cdot 14^{\mathrm{a}}$ & 0.016 & $0.17^{a, b}$ & 0.015 & 0.082 & 0.944 & 0.032 \\
\hline $18: 1 c 9 \ddagger$ & $11 \cdot 2$ & 0.45 & $13 \cdot 2$ & 0.788 & 11.2 & 0.14 & 11.5 & 0.44 & 0.052 & 0.032 & 0.081 \\
\hline $18: 1 c 11$ & $2 \cdot 11$ & 0.056 & 2.42 & 0.115 & 1.73 & 0.089 & 1.97 & 0.121 & $<0.001$ & 0.009 & 0.710 \\
\hline $18: 2 n-6$ & 16.8 & 0.61 & 15.3 & 0.671 & 20.4 & 0.74 & 19.9 & 0.51 & $<0.001$ & 0.129 & 0.414 \\
\hline $18: 3 n-3$ & 0.31 & 0.032 & 0.31 & 0.023 & 0.28 & 0.012 & 0.27 & 0.019 & 0.144 & 0.867 & 0.871 \\
\hline $18: 3 n-6 \ddagger$ & 0.13 & 0.017 & 0.16 & 0.009 & 0.08 & 0.006 & 0.08 & 0.008 & 0.017 & 0.364 & 0.534 \\
\hline $20: 0 \S$ & 0.09 & 0.009 & 0.07 & 0.007 & 0.11 & 0.014 & 0.09 & 0.006 & 0.084 & 0.014 & 0.725 \\
\hline $20: 1 c 11$ & 0.16 & 0.005 & 0.19 & 0.009 & 0.15 & 0.007 & 0.16 & 0.010 & 0.065 & 0.009 & 0.216 \\
\hline $20: 2 n-6$ & 0.43 & 0.038 & 0.46 & 0.033 & 0.60 & 0.021 & 0.62 & 0.032 & $<0.001$ & 0.490 & 0.791 \\
\hline $20: 3 n-9$ & 0.17 & 0.016 & 0.18 & 0.021 & 0.23 & 0.012 & 0.23 & 0.012 & 0.002 & 0.704 & 0.693 \\
\hline $20: 3 n-6$ & 0.64 & 0.083 & 0.50 & 0.050 & 1.47 & 0.125 & 1.32 & 0.104 & $<0.001$ & 0.141 & 0.966 \\
\hline $20: 3 n-3$ & 0.07 & 0.013 & 0.04 & 0.009 & 0.12 & 0.013 & 0.09 & 0.019 & 0.001 & 0.068 & 0.993 \\
\hline $20: 4 n-6$ & $13 \cdot 6$ & 1.41 & 12.8 & 1.31 & 11.5 & 0.530 & 11.7 & 0.97 & 0.166 & 0.775 & 0.616 \\
\hline $20: 5 n-3$ & 0.57 & 0.047 & 0.60 & 0.048 & 0.45 & 0.048 & 0.52 & 0.051 & 0.047 & 0.289 & 0.641 \\
\hline $22: 0$ & 0.56 & 0.043 & 0.64 & 0.076 & 0.64 & 0.048 & 0.65 & 0.050 & 0.412 & 0.432 & 0.519 \\
\hline $22: 4 n-6$ & 0.66 & 0.086 & 0.64 & 0.076 & 0.67 & 0.048 & 0.59 & 0.061 & 0.775 & 0.468 & 0.709 \\
\hline $22: 5 n-3$ & 1.77 & 0.247 & 1.47 & 0.241 & 1.59 & 0.117 & 1.47 & 0.179 & 0.661 & 0.310 & 0.670 \\
\hline $22: 6 n-3$ & 0.59 & 0.135 & 0.76 & 0.155 & 0.29 & 0.024 & 0.26 & 0.037 & 0.001 & 0.481 & 0.349 \\
\hline $23: 0$ & 0.07 & 0.010 & 0.08 & 0.070 & 0.11 & 0.020 & 0.12 & 0.010 & 0.004 & 0.602 & 0.789 \\
\hline Others\| & 1.71 & 0.096 & 1.90 & 0.075 & 1.61 & 0.118 & 1.55 & 0.072 & 0.021 & 0.527 & 0.182 \\
\hline \multicolumn{12}{|l|}{ Fatty acid partial sums } \\
\hline SFAT & 48.1 & 1.84 & 47.8 & 1.66 & 46.6 & 1.04 & 46.7 & 0.91 & 0.368 & 0.902 & 0.883 \\
\hline MUFA $^{\star \star}$ & 14.4 & 0.55 & 17.2 & 1.06 & 14.2 & 0.14 & 14.7 & 0.59 & 0.056 & 0.019 & 0.106 \\
\hline PUFAt† & 35.8 & 2.33 & 33.2 & 2.40 & 37.7 & 1.16 & 37.2 & 1.42 & 0.137 & 0.414 & 0.588 \\
\hline$n-6$ PUFA $\neq \ddagger$ & 32.4 & 1.99 & 29.8 & 2.04 & 34.7 & 1.12 & 34.3 & 1.25 & 0.046 & 0.380 & 0.532 \\
\hline$n-6$ LC-PUFA§§ & $15 \cdot 1$ & 1.50 & 14.1 & 1.39 & 13.8 & 0.64 & 13.8 & 1.02 & 0.514 & 0.682 & 0.662 \\
\hline$n-3$ PUFA \|\|$^{30}$ & 3.31 & 0.361 & 3.19 & 0.363 & 2.73 & 0.134 & 2.62 & 0.192 & 0.052 & 0.693 & 0.984 \\
\hline$n-3$ LC-PUFA ${ }^{\star \star \star}$ & 2.99 & 0.394 & 2.92 & 0.418 & 2.64 & 0.160 & 2.48 & 0.256 & 0.236 & 0.722 & 0.878 \\
\hline \multicolumn{12}{|l|}{ Fatty acid ratios } \\
\hline $\begin{array}{l}\text { PUFA:SFA } \\
\text { PFA }\end{array}$ & 0.77 & 0.075 & 0.72 & 0.076 & 0.82 & 0.043 & 0.80 & 0.045 & 0.290 & 0.606 & 0.757 \\
\hline$n-6: n-3$ & $10 \cdot 3$ & 0.56 & 9.83 & 0.542 & 12.98 & 0.729 & 13.46 & 0.629 & $<0.001$ & 0.990 & 0.452 \\
\hline
\end{tabular}

Lean, commercial cross-bred pigs ( $50 \%$ Large White, $25 \%$ Landrace and $25 \%$ Pietrain); fatty, Alentejana purebred pigs; NPD, normal protein diet; G $\times$ D, interaction between genotype (G) and diet (D); LC-PUFA, long-chain PUFA. a,b,c Mean values within a row with unlike superscript letters were significantly different $(P<0.05)$.

* Variable adjusted for total lipids.

$\dagger 18: 1$ trans $(18: 1 t)$ represents the sum of $18: 1$ trans6 to trans 11 . Variable adjusted for total lipids $\times G \times D$ interaction.

₹ Variable adjusted for total lipids $\times \mathrm{G}$ interaction.

II Unidentified minor fatty acids and the dimethylacetals $16: 0,18: 0$ and $18: 1$, which are derived from plasmalogens.

I SFA $=14: 0+15: 0+16: 0+17: 0+18: 0+20: 0+22: 0+23: 0$.

${ }^{*}$ MUFA $=16: 1$ cis-7 $+16: 1$ cis-9 $+17: 1$ cis-9 $9+18: 1 t+18: 1$ cis $-9+18: 1$ cis $-11+20: 1$ cis -11

t† PUFA $=18: 2 n-6+18: 3 n-3+20: 2 n-6+20: 3 n-3+20: 3 n-6+20: 3 n-9+20: 4 n-6+20: 5 n-3+22: 4 n-6+22: 5 n-3+22: 6 n-3$

拉 $n-6$ PUFA $=18: 2 n-6+20: 2 n-6+20: 3 n-6+20: 4 n-6+22: 4 n-6$.

$\S \S n-6$ LC-PUFA $=20: 4 n-6+22: 4 n-6$.

FA $=18: 3 n-3+20: 3 n-3+20: 5 n-3+22: 5 n-3+22: 6 n-3$ 
(A)

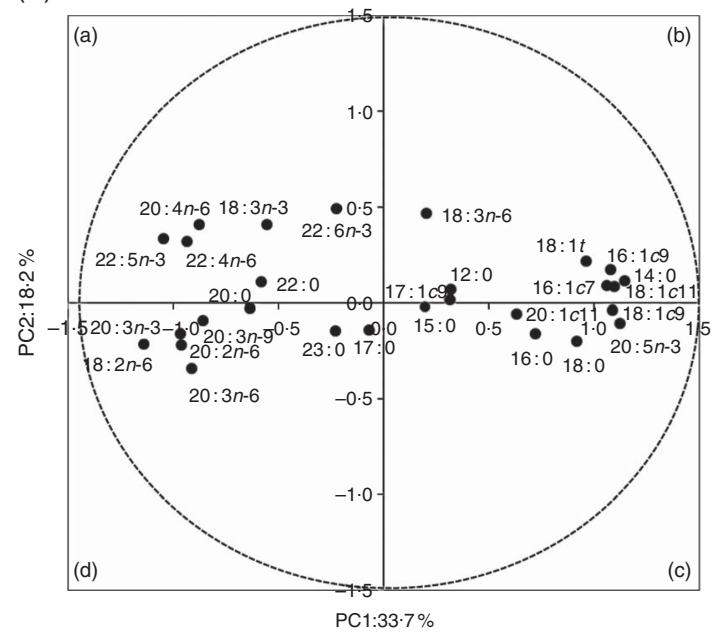

(B)

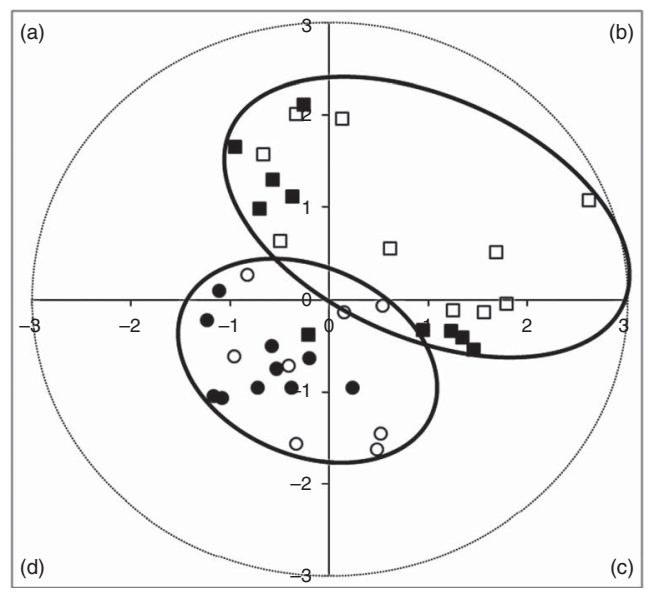

Fig. 1. Loading plot of the first and second principal components (PC) of the pooled data (A) and component score vectors (B) for hepatic fatty acid composition ( $\mu \mathrm{mol} / \mathrm{g}$ liver) from lean (commercial cross-bred pigs ( $50 \%$ Large White, $25 \%$ Landrace and $25 \%$ Pietrain)) and fatty (Alentejana purebred) pigs fed normal protein diet (NPD) and reduced protein diet (RPD). , Lean-NPD; $\square$, lean-RPD; , fatty-NPD; $\bigcirc$, fatty-RPD.

Table 5. Loadings for the first two principal components (PC)

\begin{tabular}{|c|c|c|}
\hline Variables & PC1 & PC2 \\
\hline $12: 0$ & 0.32 & 0.07 \\
\hline $14: 0$ & $1 \cdot 15$ & 0.11 \\
\hline $15: 0$ & 0.19 & -0.02 \\
\hline $16: 0$ & 0.72 & -0.16 \\
\hline $16: 1 c 7$ & 1.06 & 0.09 \\
\hline $16: 1 c 9$ & 1.08 & 0.17 \\
\hline $17: 0$ & -0.07 & -0.14 \\
\hline $17: 1 c 9$ & 0.32 & 0.01 \\
\hline $18: 0$ & 0.92 & -0.20 \\
\hline $18: 1 t$ & 0.96 & 0.21 \\
\hline $18: 1 c 9$ & 1.09 & -0.04 \\
\hline $18: 1 c 11$ & $1 \cdot 10$ & 0.08 \\
\hline $18: 2 n-6$ & -1.14 & -0.22 \\
\hline $20: 0$ & -0.63 & -0.03 \\
\hline $18: 3 n-6$ & 0.20 & 0.46 \\
\hline $20: 1 c 11$ & 0.63 & -0.05 \\
\hline $18: 3 n-3$ & -0.55 & 0.40 \\
\hline $20: 2 n-6$ & -0.96 & -0.22 \\
\hline $20: 3 n-9$ & -0.86 & -0.10 \\
\hline $22: 0$ & -0.58 & 0.11 \\
\hline $20: 3 n-6$ & -0.91 & -0.35 \\
\hline $20: 3 n-3$ & -0.97 & -0.16 \\
\hline $20: 4 n-6$ & -0.87 & 0.41 \\
\hline $20: 5 n-3$ & -0.23 & -0.15 \\
\hline $22: 4 n-6$ & -0.93 & 0.32 \\
\hline $22: 5 n-3$ & -1.04 & 0.33 \\
\hline $22: 6 n-3$ & -0.23 & 0.49 \\
\hline $23: 0$ & -0.23 & -0.15 \\
\hline
\end{tabular}

$(P<0 \cdot 01), 18: 3 n-6(P<0 \cdot 01), 22: 6 n-3(P<0 \cdot 01)$ and $20: 5 n-3$ $(P<0 \cdot 05)$. In addition, $F A S N$ mRNA levels were positively correlated with $20: 3 n-6 \quad(P<0.001), 20: 2 n-6 \quad(P<0.05)$ and $20: 3 n-9(P<0.05)$. The $S C D$ relative mRNA levels were negatively correlated with $16: 1 c 7(P<0.001), 18: 1 t(P<0.001)$, 18: $1 c 11(P<0 \cdot 01), 18: 3 n-6(P<0 \cdot 01), 20: 5 n-3(P<0 \cdot 01)$ and $22: 6 n-3 \quad(P<0 \cdot 05)$ and positively correlated with $20: 3 n-6$ $(P<0 \cdot 01)$ and $20: 3 n-3(P<0 \cdot 05)$. SREBF1 mRNA levels showed negative correlations with $16: 1 c 7 \quad(P<0 \cdot 001), 18: 1 c 11$
$(P<0.001), 18: 1 t(P<0 \cdot 01), 18: 3 n-6(P<0.05)$ and $22: 6 n-3$ $(P<0.05)$ and a positive correlation with $20: 3 n-6(P<0 \cdot 001)$. $A C A C A$ gene expression levels were negatively correlated with $16: 1 c 7 \quad(P<0.01), 18: 1 t(P<0.01), 18: 1 c 11 \quad(P<0.01)$ and $22: 6 n-3 \quad(P<0.05)$ but positively correlated with $20: 3 n-6$ $(P<0 \cdot 01)$. The CRAT gene expression was positively correlated with 20:3n-6 $(P<0.01), 18: 0(P<0.05), 18: 1 c 9(P<0.05)$, $18: 2 n-6(P<0.05)$ and $20: 3 n-3(P<0.05)$ fatty acids, and negatively correlated with $18: 1 t(P<0 \cdot 001)$.

\section{Discussion}

To the best of our knowledge, the present study is the first report on the influence of pig's genotype (50\% Large White, $25 \%$ Landrace and $25 \%$ Pietrain cross-bred pigs, a lean genotype, $v$. Alentejana purebred pigs, an autochthonous fatty genotype) and dietary protein levels (normal v. $25 \%$ reduced, not equilibrated for lysine) on hepatic fatty acid metabolism. In order to elucidate the molecular mechanisms of hepatic lipid metabolism in pigs under dietary protein restriction, the expression levels of genes encoding for key lipogenic and lipolytic enzymes and associated transcription factors were also assessed. Moreover, results on the present pig trial regarding the effect of genotype and dietary protein level on fat partitioning between adipose tissue and muscle, as well as the molecular mechanisms regulating the differential fat deposition between those tissues, are published elsewhere ${ }^{(5)}$. In brief, dietary protein reduction promoted a lipogenic effect in adipose tissue for both lean and fatty genotypes, but in muscle the lipogenic effect was only observed for lean pigs.

Fatty pigs showed higher ADFI but lower G:F values than lean pigs. This difference is likely due to the higher energy value of body weight gain in fatty pigs. However, ADG was unaffected by both genotype and diet. In contrast, low-protein ${ }^{(36)}$ and lysinedeficient ${ }^{(37)}$ diets decreased ADG in lean pigs during the growing phase. Detailed information about pigs' performance and feed efficiency is available in the study by Madeira et $a l{ }^{(38)}$. 
(A)

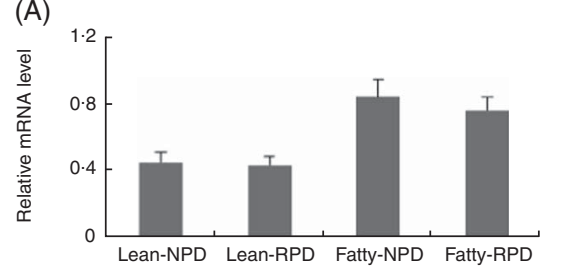

(D)

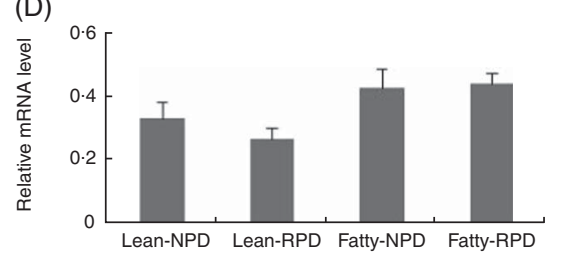

(G)

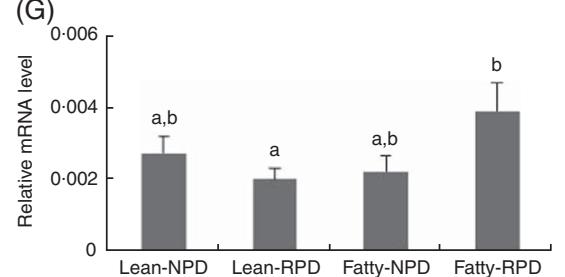

(J)

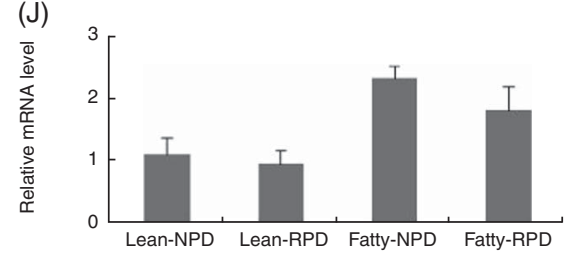

(B)

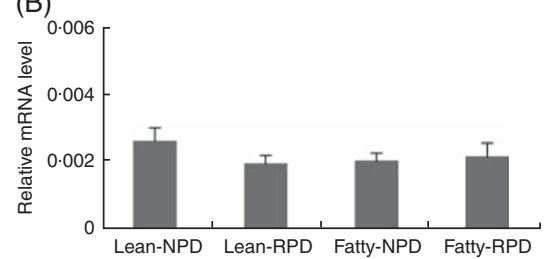

(E)

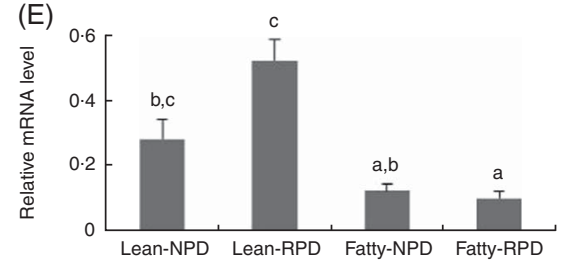

(in)
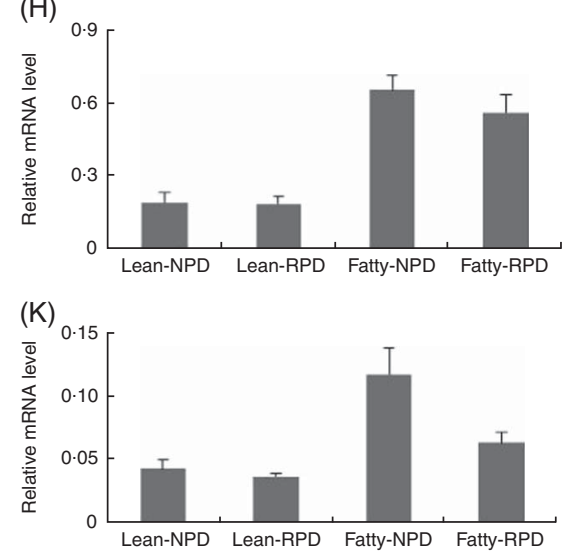

(C)

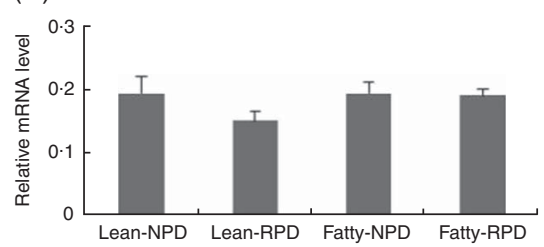

$(\mathrm{F})$

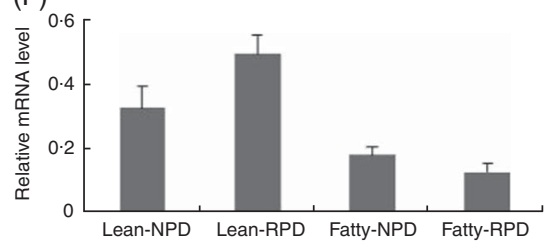

(I)

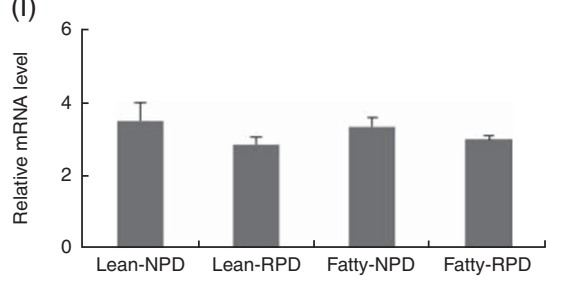

Fig. 2. Effect of the reduced protein diet (RPD) on gene expression levels in the liver of lean (commercial cross-bred pigs ( $50 \%$ Large White, $25 \%$ Landrace and $25 \%$ Pietrain)) and fatty (Alentejana purebred) pigs: (A) acetyl-CoA carboxylase $a$ (genotype, $P<0.001$ ), (B) CCAAT/enhancer-binding protein $a$, (C) carbohydrate response element-binding protein, (D) carnitine $O$-acetyltransferase (genotype, $P=0.006$ ), (E) fatty acid desaturase 1 (FADS1) (genotype $\times$ diet, $P=0.031$ ), (F) fatty acid desaturase 2 (FADS2), (G) fatty acid-binding protein 4 (FABP4) (genotype $\times$ diet, $P=0.032$ ), (H) fatty acid synthase (FASN) (genotype, $P<0.001$ ), (I) PPARa, (J) stearoyl-CoA desaturase (SCD) (genotype, $P<0.001$ ) and $(\mathrm{K})$ sterol regulatory element-binding factor 1 (SREBF1) (genotype, $P<0.001$; diet, $P=0.023)$. Values are means, with their standard errors represented by vertical bars. ${ }^{a, b, c}$ Mean values within a row with unlike letters were statistically different $(P<0.05)$. 'Genotype', 'diet' and 'genotype $\times$ diet' mean significant effect of genotype, diet or interaction between genotype and diet, respectively. For FADS1 and FADS2, the variables were adjusted for total lipids $\times$ genotype $\times$ diet interaction. NPD, normal protein diet.

Regarding genotype, total lipids, phospholipids, total cholesterol and LDL-cholesterol in plasma were higher in lean pigs, whereas HDL-cholesterol was higher in fatty pigs. This finding might be explained by the higher energy needed for the greater protein biosynthesis rate in lean pigs. Delta5 and delta6 desaturases are required for the synthesis of long-chain PUFA that are mainly esterified into phospholipids. These enzymes are widely expressed in mammalian tissues, with the highest levels found in the liver ${ }^{(12)}$. Cholesterol is partially obtained from the diet, through the consumption of animal-derived products, and from de novo biosynthesis in the liver ${ }^{(39)}$. In the present study, the higher levels of LDL-cholesterol found in lean pigs, contrasting with lower HDL-cholesterol, might result on slightly higher proportions of $n-3$ PUFA $(P=0.052)$ in the liver.

For hepatic markers, ALT and GGT activities were higher in fatty pigs, whereas ALP activity was inversely higher in lean pigs. Despite the increase in ALT and GGT activities in the fatty genotype, it is worth noticing that the levels found are still within the reference values for pigs, which are 31-58 and $10-52 \mathrm{U} / 1$, respectively ${ }^{(40)}$. The restriction of dietary protein did not affect plasma hepatic markers or total lipids, but increased TAG, VLDL-cholesterol and FFA. This finding is consistent with the higher values obtained for total fatty acids in subcutaneous adipose tissue of lean and fatty pigs fed RPD ${ }^{(5)}$. In fact, VLDL are produced in the liver and transport endogenous TAG and cholesterol, which are removed from the blood stream for storage in adipose tissue through lipoprotein lipase action.

Insulin levels were higher in fatty pigs, which can be explained by the higher proportion of hepatic $n-6$ PUFA found in this genotype ${ }^{(41)}$. In fact, previous studies have shown that young pigs fed low-protein diets in comparison with highprotein diets produced lower glucose and insulin systemic levels ${ }^{(42,43)}$. Regarding the possibility of insulin resistance occurrence, Blat et al. ${ }^{(44)}$ reported that piglets receiving high-protein diets had higher insulin concentrations, and concomitantly higher HOMA-IR, compared with piglets receiving the NPD. Nevertheless, the values found for insulin resistance index were, once again, within the normal physiological range, that is, $<2 \cdot 4^{(44)}$. In our study, only fatty pigs fed the NPD had an HOMA-IR above this reference value. Insulin stimulates fatty 
Table 6. Pearson's correlation coefficients between fatty acid composition ( $\mu \mathrm{mol} / \mathrm{g}$ liver) and gene expression levels (relative mRNA level) in the liver of lean and fatty pigs fed normal and reduced protein diets

\begin{tabular}{|c|c|c|c|c|c|c|c|c|c|c|c|}
\hline Fatty acids & $A C A C A$ & CEBPA & ChREBP & CRAT & FADS1 & FADS2 & FABP4 & FASN & PPARA & $S C D$ & SREBF1 \\
\hline \multicolumn{12}{|l|}{$12: 0$} \\
\hline $14: 0$ & & & & & $0.54^{\star \star \star}$ & $0.50^{\star *}$ & & & & & \\
\hline $15: 0$ & & & & & & & & & & & \\
\hline $16: 0$ & & & & & & & $0.37^{*}$ & & & & \\
\hline $16: 1 c 7$ & $-0.47^{* *}$ & & & & & & & $-0.58^{\star \star \star}$ & & $-0.57^{\star \star *}$ & $-0.58^{\star * *}$ \\
\hline $16: 1 c 9$ & & & & & $0.42^{\star \star}$ & $0.34^{*}$ & & & & & \\
\hline \multicolumn{12}{|l|}{$17: 0$} \\
\hline \multicolumn{12}{|l|}{$17: 1 c 9$} \\
\hline 18:0 & & & & $0 \cdot 36^{\star}$ & & & & & & & \\
\hline $18: 1 t$ & $-0.45^{\star \star}$ & & $-0.33^{\star}$ & $-0.51^{\star * *}$ & & $0.53^{\star \star \star}$ & $0.48^{\star \star}$ & $-0.62^{\star \star \star}$ & & $-0.55^{\star \star \star}$ & $-0.41^{\star \star}$ \\
\hline $18: 1 c 9$ & & & & $0.32^{*}$ & & & & & & & \\
\hline $18: 1 c 11$ & $-0.42^{\star *}$ & & & & & & & $-0.50^{\star \star}$ & & $-0.48^{\star \star}$ & $-0.52^{\star \star \star}$ \\
\hline $18: 2 n-6$ & & & & $0.39^{*}$ & $-0.57^{\star \star \star}$ & $-0.57^{\star \star \star}$ & & & & & \\
\hline $20: 0$ & & & & & $-0.37^{\star}$ & $-0.39^{\star}$ & & & & & \\
\hline $18: 3 n-6$ & & & & & $0.38^{\star}$ & $0.35^{\star}$ & & $-0.49^{\star \star}$ & & $-0.41^{\star \star}$ & $-0.37^{\star}$ \\
\hline \multicolumn{12}{|l|}{$20: 1 c 11$} \\
\hline \multicolumn{12}{|l|}{$18: 3 n-3$} \\
\hline $20: 2 n-6$ & & & & & $-0.58^{\star \star \star}$ & $-0.57^{\star \star *}$ & & $0.34^{*}$ & & & \\
\hline $20: 3 n-9$ & & & & & $-0.36^{\star}$ & $-0.37^{\star}$ & & $0.33^{*}$ & & & \\
\hline \multicolumn{12}{|l|}{$22: 0$} \\
\hline $20: 3 n-6$ & $0.41^{* *}$ & & & $0.46^{* *}$ & $-0.65^{\star \star \star}$ & $-0.59^{\star \star *}$ & & $0.53^{\star \star *}$ & & $0.46^{\star *}$ & $0.31^{* * *}$ \\
\hline $20: 3 n-3$ & & & & $0.33^{*}$ & $-0.54^{\star \star \star}$ & $-0.49^{\star *}$ & & & & $0.32^{*}$ & \\
\hline \multicolumn{12}{|l|}{$20: 4 n-6$} \\
\hline $20: 5 n-3$ & & & & & & & & $-0.34^{\star}$ & & $-0.43^{\star *}$ & \\
\hline \multicolumn{12}{|l|}{$22: 4 n-6$} \\
\hline \multicolumn{12}{|l|}{$22: 5 n-3$} \\
\hline $22: 6 n-3$ & $-0.32^{*}$ & & & & & & & $-0.46^{\star *}$ & & $-0.37^{\star}$ & $-0.34^{*}$ \\
\hline $23: 0$ & & & & & $0.44^{\star *}$ & $0.39^{*}$ & & & & & \\
\hline
\end{tabular}

ACACA, acetyl-CoA carboxylase $\alpha$; CEBPA, CCAAT/enhancer-binding protein $a$; ChREBP, carbohydrate response element-binding protein; CRAT, carnitine O-acetyltransferase; FADS1, fatty acid desaturase 1; FADS2, fatty acid desaturase 2; FABP4, fatty acid binding protein 4; FASN, fatty acid synthase; SCD, stearoyl-CoA desaturase; SREBF1, sterol regulatory element-binding factor 1.

Significant correlation: ${ }^{\star} P<0.05,{ }^{\star *} P<0.01,{ }^{\star \star *} P<0.001$.

acid synthesis in the liver with formation and storage of TAG ${ }^{(45)}$.

This might be the justification for higher total lipids found in the liver of fatty pigs.

Leptin and urea were influenced by genotype, with higher levels of both variables in fatty pigs. Leptin is almost exclusively secreted by adipocytes ${ }^{(46)}$, which could explain the higher leptin concentrations found in the fatty genotype. FABP4 plays a key role in fatty acid transport and oxidation, and increases synergistically with leptin during adipose tissue inflammation $^{(47)}$. A significant interaction between genotype and diet was observed for FABP4 expression level, with an increase in fatty pigs fed RPD when compared with the lean ones. This finding also agrees with higher leptin levels found in the fatty genotype.

The higher level of urea found in plasma of fatty pigs, relative to lean pigs, may rely on the genetic selection towards higher amino acid deposition, and therefore lower urea excretion. The same effect has been demonstrated in genetically obese rats ${ }^{(48)}$. In contrast with other reports ${ }^{(49,50)}$, the restriction of dietary protein decreased plasma urea levels, thus indicating unaffected renal function. The circumstance that restriction of dietary protein only diminished plasma total protein in lean pigs, but not in fatty pigs, might be related to a higher responsiveness of this genotype towards the reduced protein feeding treatment.

An influence of genotype was observed for hepatic total lipids, with fatty pigs showing higher values than lean pigs. This effect might be explained by higher TAG:phospholipid ratios in fatty pigs, knowing that phospholipid content is highly conserved on cellular membranes ${ }^{(51)}$. In addition, this finding concurs with an up-regulation of $S C D$ in fatty pigs relative to lean pigs, and also confirms the major proportion of fatty acids found in the fatty genotype. Similar results were previously reported for both muscle and subcutaneous adipose tissue ${ }^{(5)}$. The up-regulated expression of $A C A C A$ and SREBF1 genes observed in fatty pigs, when compared with lean pigs, may represent an increased capacity for de novo hepatic lipogenesis. Earlier studies have recognised a regulatory role for transcriptional factors in the liver, fat depots or both tissues in pigs ${ }^{(52-54)}$. The de novo lipogenesis is strongly promoted by SREBF1 activity (most of the genes encoding enzymes involved in fatty acid synthesis are SREBF1c targets), as this transcriptional regulator induces transcription of genes encoding for ACACA, FASN and SCD enzymes, all of them responsible for fatty acid synthesis $^{(7)}$.

Conversely, the restriction of dietary protein had no effect on hepatic total lipids, which concur, following the above described reasoning, with the non-variation of the lipogenic enzyme SCD. It was previously reported that feeding low-protein diets to pigs does not affect backfat thickness, although a small increase in total fatty acid content in both lean (4\%) and fatty (6\%) genotypes was observed in subcutaneous adipose tissue $^{(5)}$. However, this increase was not followed by an up-regulation of the expression of the lipogenic enzyme SCD in subcutaneous adipose tissue with $\mathrm{RPD}^{(5)}$. In contrast, RPD 
increased IMF content in lean but not in fatty pigs ${ }^{(38)}$. The increase in IMF obtained in this pig trial for the lean genotype fed a $25 \% \operatorname{RPD}(17.5 \mathrm{v} .13 \cdot 1 \%$ of crude protein) was $40 \%$. In addition, we have also demonstrated that this lipogenic response in skeletal muscle was due to the limitation of lysine in the diets. The results of mRNA expression in muscle suggest that the genotype-specific effect of RPD on IMF is mediated via up-regulation of the lipogenic enzyme SCD and the adipogenic transcription factor $P P A R G^{(5)}$. Therefore, in contrast to muscle (confirmed for lean genotype) and subcutaneous adipose tissue (confirmed for both lean and fatty genotypes), RPD did not promote a lipogenic response in the liver of both genotypes, lean or fatty. This suggests that the restriction of dietary protein does not seem to promote, in the long-term, fatty liver, which is a pathophysiological condition associated with several metabolic disorders, in particular obesity, diabetes and hyperlipidaemia $^{(55,56)}$.

Moreover, the restriction of dietary protein increased MUFA percentages in the liver, as illustrated by $18: 1 c 9$ fatty acid variations. This result was not corroborated by SCD mRNA expression level, which was unaffected by RPD, as already stated. SCD is the key enzyme required for the biosynthesis of unsaturated fatty acids, which catalyses the 9-cis desaturation of saturated fatty acyl-CoA ${ }^{(57)}$. Moreover, in a study using Landrace castrated pigs fed RPD containing plant oils, the SCD-1 protein expression was not affected by these diets in the liver ${ }^{(58)}$

Long-chain PUFA synthesis is dependent on FADS1 and FADS2 desaturases ${ }^{(12)}$. Their coordinated action is supported by our own findings, that is, both enzymes presented significant correlations with the same long-chain PUFA. Moreover, FADS1 mRNA expression was higher in the lean genotype fed the restricted protein diet. In line with this finding, the $20: 5 n-3$ fatty acid percentage increased in lean pigs. In addition, the RPD decreased PUFA in muscle and subcutaneous adipose tissue in both genotypes ${ }^{(5)}$. In the liver, no significant interactions were observed on fatty acid composition, except for the minor $18: 1 t$ fatty acids.

Transcriptional regulation is one of the several mechanisms affecting hepatic fatty acid metabolism. Two transcriptional factors, SREBF1 and PPARA, appear to be the key players in the biosynthesis and degradation of fatty acids, respectively ${ }^{(59)}$. However, this fact was not confirmed in this study for PPARA, whose mRNA levels were similar across experimental groups. Our results showed a clear effect of genotype for SREBF1 with higher mRNA expression levels in fatty pigs rather than in lean pigs. This finding is, once again, probably related to increased plasma insulin, leptin and HDL-cholesterol concentrations in fatty pigs. Insulin is a well-known stimulator of lipogenesis and activates the hepatic expression of $S R E B F 1^{(60)}$, which in turn is involved in the regulation of genes controlling cholesterol availability $^{(61)}$.

The restriction of dietary protein was able to significantly down-regulate SREBF1 mRNA transcriptional levels in both genotypes, suggesting decreased biosynthesis of fat and, most probably, of fatty acid elongation. In line with this, the gene expression levels of $A C A C A$ and FASN showed the same trend as that of $S R E B F 1$ gene, even if the dietary treatments presented no statistical significance. Previous studies have demonstrated that $A C A C A$ and FASN genes are regulated in the liver by other nutritional factors, rather than dietary protein level, such as glucose, fasting/feeding, high-fat and PUFA availability ${ }^{(18,59,62)}$. In a study with Landrace castrate pigs fed RPD supplemented with plant oils, SREBF1c protein expression was not affected by RPD, but ACACA and FASN had decreased protein expressions in the liver ${ }^{(58)}$.

As previously reported, fatty acid composition of skeletal muscle and subcutaneous adipose tissue was much more modulated by pig genotype than by dietary protein reduction ${ }^{(5)}$. The same finding was observed for hepatic fatty acids. The discriminant analysis presented here, a PCA based on the relationship among hepatic individual fatty acids, shows a clear separation of genotypes. The marked differences between short- and medium-chain MUFA $(16: 1 c 7,16: 1 c 9$ and $18: 1 c 11)$ and long-chain PUFA ( $20: 2 n-6,20: 3 n-9,20: 3 n-6,20: 3 n-3)$, as well as $18: 2 n-6$ proportions, which characterise the fatty acid profiles of lean and fatty pigs may have contributed for this discrimination. Curiously, for the lean genotype, and in contrast with the fatty genotype, a higher dispersion pattern of cases was observed. One can speculate that higher genetic variability in lean pigs relative to fatty pigs might be responsible for the observed scatter pattern. This remains to be further elucidated.

\section{Conclusions}

The present study is the first report on the effects, individual or combined, of restriction of dietary protein level (17.5 v. 13.1\%) and distinct genotypes of pigs (lean $v$. fatty) on hepatic fatty acid metabolism.

The effect of genotype was the determinant factor for total lipids in plasma and the liver, as well as for hepatic fatty acid composition, because these are two genetic lines of pigs with distinct fat deposition rates. It has been shown that hepatic lipogenesis can be modified in response to genetic selection, as the gene expression levels of key lipogenic enzymes and their associated transcription factors were more affected by genotype than by diet.

The restriction of dietary protein impacted negatively on systemic TAG, FFA and VLDL-cholesterol but promoted no change in total lipids in the liver. Therefore, dietary protein reduction does not seem to enhance fatty acid deposition in the liver, contrary to what has been reported on adipose tissue (both in lean and fatty genotypes) and muscle (only in lean genotype). Thus, these results suggest a tissue-specific lipogenic response of liver to RPD, when compared with adipose tissue and muscle. Ultimately, the restriction of dietary protein does not seem to account for fatty liver development.

However, to a small extent, there is a pig genotype-specific effect of dietary protein restriction on hepatic lipid metabolism, which seems to be mediated by the differential expression levels of FADS1 and FABP4 genes.

Taken together, these data contribute to a better understanding on the molecular mechanisms of dietary protein level on fat partitioning in lean and fatty pigs. The results presented here indicate that the restriction of dietary protein does not promote hepatic lipogenesis in lean or fatty pigs, which is in 
contrast to the effect described for muscle (only lipogenesis in lean pigs) and adipose tissue (lipogenesis in both lean and fatty pigs). This genotype-specific effect of dietary protein restriction on lipid metabolism in pigs stresses the importance of devising custom-made feeding strategies that take into account the genetic background.

\section{Acknowledgements}

The authors are grateful to Eng. J. Santos Silva and Eng. António Sequeira from the Unidade de Investigação em Produção Animal for technical assistance.

The authors acknowledge the financial support from Fundação para a Ciência e a Tecnologia (FCT) grant (PTDC/CVT/ 99210/2008), CIISA project (UID/CVT/00276/2013) and individual fellowships to M. S. M. (SFRH/BPD/97432/2013) and S. V. M. (SFRH/BPD/63019/2009). V. M. R. P. is an assistant researcher supported through an IF-FCT contract (2013 FCT investigator). P. A. L. is a researcher from the FCT programme 'Ciência 2008' and Incentivo 2014 project (AGR/UI0276/2014). This funding contributed to conduct the study and to analyse the samples.

M. S. M., V. M. R. P., C. M. A., P. A. L., S. V. M., R. M. A. P. and J. A. M. P. performed tissue sampling, laboratory work and prepared the manuscript. M. S. M., V. M. R. P., C. M. A., P. A. L. and J. A. M. P. were responsible for the interpretation of the results and preparation of the manuscript. J. A. M. P. was responsible for the study design.

All the authors read and approved the findings of the study. The authors declare that there are no conflicts of interest.

\section{References}

1. Dodson MV, Hausman GJ, Guan L, et al. (2010) Lipid metabolism, adipocyte depot physiology and utilization of meat animals as experimental models for metabolic research. Int J Biol Sci 6, 691-699.

2. DeVol DL, McKeith FK, Bechtel PJ, et al. (1988) Variation in composition and palatability traits and relationships between muscle characteristics and palatability in a random sample of pork carcasses. J Anim Sci 66, 385-395.

3. Doran O, Moule SK, Teye GA, et al. (2006) A reduced protein diet induces stearoyl-CoA desaturase protein expression in pig muscle but not in subcutaneous adipose tissue: relationship with intramuscular lipid formation. Br J Nutr 95, 609-617.

4. D'Souza DN, Pethick DW, Dunshea FR, et al. (2008) Reducing the lysine to energy content in the grower growth phase diet increases intramuscular fat and improves the eating quality of the 563 longissimus thoracis muscle of gilts. Aust J Exp Agric 48, 1105-1109.

5. Madeira MS, Pires VMR, Alfaia CM, et al. (2013) Differential effects of reduced protein diets on fatty acid composition and gene expression in muscle and subcutaneous adipose tissue of Alentejana purebred and Large White $\times$ Landrace $\times$ Pietrain crossbred pigs. Br J Nutr 110, 216-229.

6. Witte DP, Ellis M, Mckeith FK, et al. (2000) Effect of dietary lysine level and environmental temperature during the finishing phase on the intramuscular fat content of pork. J Anim Sci 78, 1272-1276.

7. Horton JD, Golstein JL \& Brown MS (2002) SREBPs: activators of the complete program of cholesterol and fatty acid synthesis in the liver. J Clin Invest 109, 1125-1131.
8. Schadinger SE, Bucher NLR, Schreiber BM, et al. (2005) PPARgamma2 regulated lipogenesis and lipid accumulation in steatotic hepatocytes. Am J Physiol Endocrinol Metab 288, $1195-1205$.

9. Corominas J, Ramayo-Caldas Y, Puig-Oliveras A, et al. (2013) Analysis of porcine adipose tissue transcriptome reveals differenced in the novo fatty acid synthesis in pigs with divergent muscle fatty acid composition. BMC Genomics 14, 843.

10. Nafikov RA \& Beitz DC (2007) Carbohydrate and lipid metabolism in farm animals. J Nutr 137, 702-705.

11. Vallim T \& Salter AM (2010) Regulation of hepatic gene expression by saturated fatty acids. Prostaglandins Leukot Essent Fatty Acids 82, 211-218.

12. Nakamura MT \& Nara TY (2004) Structure, function, and dietary regulation of delta6, delta5, and delta9 desaturases. Ann Rev Nutr 24, 345-376.

13. Zhao S, Wang J, Song X, et al. (2010) Impact of dietary protein on lipid metabolism-related gene expression in porcine adipose tissue. Nutr Metab 7, 6.

14. Denechaud PD, Bossard P \& Lobaccaro JM (2008) ChREBP, but not LXRs, is required for the induction of glucoseregulated genes in mouse liver. J Clin Invest 118, 956-964.

15. Hocquette JF, Gondret F, Baéza E, et al. (2010) Intramuscular fat content in meat-producing animals: development, genetic and nutritional control and identification of putative markers. Animal 4, 303-319.

16. Garcia-Vaverde R, Barea R, Lara L, et al. (2008) The effects of feeding level upon protein and fat deposition in Iberian heavy pigs. Livest Sci 114, 264-273.

17. Ramalho F (2007) Apectos de produção do porco de Raça Alentejana (Production aspects of the Alentejana pig breed). Suinicultura 75, 68-69.

18. Association of Official Analytical Chemists (2000) Official Methods of Analysis, 17th ed. Arlington, VA: AOAC.

19. Clegg KM (1956) The application of the anthrone reagent to the estimation of starch in cereals. J Sci Food Agric 70, $40-44$.

20. Sukhija PS \& Palmquist DL (1988) Rapid method for determination of total fatty acid content and composition of feedstuffs and feces. J Agric Food Chem 36, 1202-1206.

21. Association of Official Analytical Chemists (2005) Amino acid analysis using Zorbax Eclipse-AAA columns and the Agilent 1100 HPLC. In Official Methods of Analysis of the Association of Official Analytical Chemists International, 18th ed., p. 473 [GW Latimer and W Horwitz, editors]. Gaithersburg, MD: AOAC International.

22. Henderson JW, Ricker RD, Bidlingmeyer BA, et al. (2000) Rapid, Accurate, Sensitive and Reproducible Analysis of Amino Acids. Palo Alto, CA: Agilent Technologies.

23. Friedewald WT, Levy RI \& Fredrickson DS (1972) Estimation of the concentration of low-density lipoprotein cholesterol in plasma, without use of the preparative ultracentrifuge. Clin Chem 18, 499-502.

24. Covaci A, Voorspoels S, Thomsen C, et al. (2006) Evaluation of total lipids using enzymatic methods for the normalization of persistent organic pollutant levels in serum. Sci Total Environ 366, 361-366.

25. Matthews DR, Hosker JP, Rudenski AS, et al. (1985) Homeostasis model assessment: insulin resistance and betacell function from fasting plasma glucose and insulin concentrations in man. Diabetologia 28, 412-419.

26. Folch J, Lees M \& Stanley GH (1957) A simple method for the isolation and purification of total lipides from animal tissues. J Biol Chem 226, 497-509.

27. Carlson LA (1985) Extraction of lipids from human whole serum and lipoproteins and from rat liver tissue with 
methylene chloride-methanol: a comparison with extraction chloroform-methanol. Clin Chim Acta 149, 89-93.

28. Raes K, De Smet SD \& Demeyer D (2001) Effect of doublemuscling in Belgian Blue young bulls on the intramuscular fatty acid composition with emphasis on conjugated linoleic acid and polyunsaturated fatty acids. Anim Sci 73, 253-260.

29. Alves SP \& Bessa RJB (2009) Comparison of two gas-liquid chromatograph columns for the analysis of fatty acids in ruminant meat. I Chromatogr A 1216, 5130-5139.

30. Vandesompele J, De Preter K \& Pattyn F (2002) Accurate normalization of real-time quantitative RT-PCR data by geometric averaging of multiple internal control genes. Genome Biol 3, 7.

31. Andersen CL, Jensen JL \& Orntoft TF (2004) Normalization of real-time quantitative reverse transcription-PCR data: a model-based variance estimation approach to identify genes suited for normalization, applied to bladder and colon cancer data sets. Cancer Res 64, 5245-5250.

32. Livak KJ \& Schmittgen TD (2001) Analysis of relative gene expression data using real-time quantitative PCR and the 2(-Delta C(T)) Method. Methods 25, 402-408.

33. Fleige S, Walf V \& Huch S (2006) Comparison of relative mRNA quantification models and the impact of RNA integrity in quantitative real-time RT-PCR. Biotechnol Lett $\mathbf{2 8}$, 1601-1613.

34. SAS Institute Inc (2009) SAS/STAT 9.2 User's Guide, 2nd ed. Cary, NC: SAS Institute Inc.

35. Milliken GA \& Johnson DE (2002) Analysis of Messy Data, Volume III: Analysis of Covariance. London: Chapman and Hall/CRC.

36. Teye GA, Sheard PR, Whittington FM, et al. (2006) Influence of dietary oils and protein level on pork quality. 1. Effects on muscle fatty acid composition, carcass, meat and eating quality. Meat Sci 73, 157-165.

37. O'Connell MK, Lynch PB \& O'Doherty JV (2006) The effect of dietary lysine restriction during the grower phase and subsequent dietary lysine concentration during the realimentation phase on the performance, carcass characteristics and nitrogen balance of growing-finishing pigs. Livest Sci 101, 169-179.

38. Madeira MS, Costa P, Alfaia CM, et al. (2013) The increased intramuscular fat promoted by dietary lysine restriction in lean but not in fatty pig genotypes improves pork sensory attributes. J Anim Sci 91, 3177-3187.

39. O'Hea EK \& Leveille GA (1969) Lipid biosynthesis and transport in the domestic chick (Gallus domesticus). Comp Biochem Physiol 30, 149-159.

40. Jackson PGG \& Cockcroft PD (2002) Laboratory reference values: biochemistry. In Clinical Examination of Farm Animals, Appendix 3, pp. 303-305. Oxford: Blackwell Science.

41. Patterson E, Wall R, Fitzgerald GF, et al. (2012) Health implications of high dietary omega-6 polyunsaturated fatty acids. $J$ Nutr Metab 2012, 539426.

42. Atinmo T, Baldijao C, Pond WG, et al. (1976) Maternal protein malnutrition during gestation alone and its effects on plasma insulin levels of the pregnant pigs, its foetuses and the developing offspring. J Nutr 106, 1647-1653.

43. Caperna TJ, Steele NC, Komarck DR, et al. (1990) Influence of dietary protein and recombinant porcine somatotropin administration in young pigs: growth, body composition and hormone status. J Anim Sci 68,4243 .
44. Blat S, Morise A, Sauret A, et al. (2012) The protein level of isoenergetic formulae does not modulate postprandial insulin secretion in piglets and has no consequences on later glucose tolerance. Br J Nutr 108, 102-112.

45. Wilcox G (2005) Insulin and insulin resistance. Clin Biochem Rev 26, 19-39.

46. Savage DB \& O'Rahilly S (2002) Leptin: a novel therapeutic role in lipodystrophy. J Clin Invest 109, 1285-1286.

47. Gan L, Liu Z, Cao W, et al. (2015) FABP4 reversed the regulation of leptin on mitochondrial fatty acid oxidation in mice adipocytes. Sci Rep 5, 13588.

48. Herrero MC, Remesar X, Arola L, et al. (1994) Splanchnic ammonia management in genetic and dietary obesity in the rat. Int J Obes Relat Metab Disord 18, 255-261.

49. Matthews JO, Southern LL, Pontif JE, et al. (1998) Interative effects of betaine, crude protein and net energy in finishing pigs. J Anim Sci 76, 2444-2455.

50. Gomez RS, Lewis AJ, Miller PS, et al. (2002) Growth performance, diet apparent digestibility, and plasma metabolite concentrations of barrows fed corn-soybean meal diets or low-protein, amino acid-supplemented diets at different feeding level. J Anim Sci 80, 644-653.

51. Ntawubizi M, Raes K, Buys N, et al. (2009) Effect of sire and sex on the intramuscular fatty acid profile and indices for enzyme activities in pigs. Livest Sci 122, 264-270.

52. Kersten S, Seydoux J, Peters JM, et al. (1999) Peroxisome proliferator-activated receptor alpha mediates the adaptive response to fasting. J Clin Invest 103, 1489-1498.

53. Mcneel RL, Ding ST, Smith EO, et al. (2000) Effect of feed restriction on adipose tissue transcript concentrations in genetically lean and obese pigs. J Anim Sci 78, 934-942.

54. Cheng PT \& Mukherjee R (2005) PPARs as targets for metabolic and cardiovascular diseases. Mini Rev Med Chem $\mathbf{5}$, 741-753.

55. Lim S, Oh TJ \& Koh KK (2015) Mechanisms link between nonalcoholic fatty liver disease and cardiometabolic disorders. Int J Cardiol 201, 408-414.

56. Kirpich IA, Marsano LS \& McClain CJ (2015) Gut-liver axis, nutrition, and non-alcoholic fatty liver disease. Clin Biochem 48, 923-930.

57. Ntambi JM (1999) Regulation of stearoyl-CoA desaturase by polyunsaturated fatty acids and cholesterol. J Lipid Res $\mathbf{4 0}$, $1549-1558$

58. Dannenberger D, Nuernberg K \& Nuernberg G (2014) Impact of dietary protein level and source of polyunsaturated fatty acids on lipid metabolism-related protein expression and fatty acid concentrations in porcine tissues. J Agric Food Chem $\mathbf{6 2}$, 12453-12461.

59. Guillon H, Martin PGP \& Pineau T (2008) Transcriptional regulation of hepatic fatty acid metabolism. In Lipids in Health and Disease, Chapter 1, pp. 3-47 [PJ Quinn and X Wang, editors]. London: Springer Science + Business Media B.V.

60. Osborne TF (2000) Sterol regulatory element-binding proteins (SREBPs): key regulators of nutritional homeostasis and insulin action. $J$ Biol Chem 275, 32379-32382.

61. Wang X, Sato R, Brown MS, et al. (1994) SREBP-1, a membrane-bound transcription factor released by sterol-regulated proteolysis. Cell 77, 53-62.

62. Flowers MT \& Ntambi JM (2008) Role of stearoyl-coenzyme A desaturase in regulating lipid metabolism. Curr Opin Lipidol 9, 248-256. 